\title{
Research on Countermeasures of Agricultural Insurance Promoting Accurate Poverty Alleviation
}

\author{
Sisi Wang \\ Great Wall College \\ China University of Geosciences \\ Baoding, China 071000
}

\begin{abstract}
Under the background of rural financial reform, the use of financial and insurance tools to achieve accurate poverty alleviation has become a popular way. The Central Document No. 1 has put forward relevant contents on accelerating the development of policy-oriented agricultural insurance for many years. Insurance helping accurate poverty alleviation has the advantages of mechanism, service and capital. By analyzing the Practice of Domestic Agricultural Insurance Promoting Accurate Poverty alleviation, the main purpose of this article is to explore innovative mechanisms that combine agricultural insurance and precision poverty alleviation. This article analyzes the problems existing in Agricultural Insurance Promoting Accurate Poverty Alleviation; It also proposes several suggestions for the study of related issues by taking Agricultural Insurance as a Point of Poverty Alleviation.
\end{abstract}

Keywords-agricultural insurance; accurate poverty alleviation; poverty alleviation

\section{INTRODUCTION}

Accurate Poverty Alleviation is the Basic Strategy for China's Development of poverty alleviation under the New Situation of Poverty alleviation, and it is also the inheritance and innovation of past poverty alleviation theories opening up a new path of rural poverty management in China. In June 2015, Xi Jinping pointed out that it is necessary for promoting accurate poverty alleviation and accurate poverty reduction to be better and Ensuring the goal of poverty alleviation is achieved .Meanwhile he put forward the idea of "six precisions". That is, "Targeted poverty alleviation, precise project arrangement, accurate use of funds, accurate measures for households, accurate distribution of villages, and accurate results in poverty eradication." And also in the 19th report, He proposed to focus on the task of poverty alleviation in poor and impoverished areas ensuring the goal of poverty alleviation would be completed by 2020 and all rural poor people would be out of poverty. He also proposed to solve the overall poverty in the region so that they can get rid of poverty and get out of poverty.

With the increasing intensity increases and the deeper degree deepens of Accurate poverty alleviation and the improvement of poverty alleviation standards. The difficulty of accurate poverty alleviation has gradually increased, and the methods of poverty alleviation have also encountered bottlenecks. However, at present, the research on agricultural insurance assisting in accurate poverty alleviation is lagging behind. Therefore, the promotion of poverty alleviation by agricultural insurance will surely become an important way to implement accurate poverty alleviation work with the positive guidance of the central government's policies and the active exploration of agricultural insurance institutions. Therefore, China's agricultural insurance must accelerate the pace of innovation and development in order to solve the problems in the process of accurate poverty alleviation.

\section{THE NECESSITY OF ACCELERATING AgRICULTURAL INSURANCE TO PROMOTE ACCURATE POVERTY ALLEVIATION}

Since China has promoted the deepening reform of rural finance, agricultural insurance has gradually gained attention. And the scale of agricultural insurance is constantly expanding. For example, in 2013, China's agricultural insurance premium income was 30.66 billion yuan, a yearon-year increase of $27.4 \%$. Compensation paid to 31.77 million affected farmers was 20.86 billion yuan, a year-onyear increase of $41 \%$.China's agricultural insurance has played an important role in strengthening the prevention and control of agricultural risks and promoting poverty alleviation in rural areas.However, there are still some outstanding problems in the poverty alleviation of agricultural insurance from the perspective of accurate poverty alleviation, which restricts its poverty alleviation function.

\section{A. Agricultural Insurance Subsidies Are Inaccurate}

Since 2007, the agricultural insurance subsidies have become inaccurate. First of all, the subsidy rate for agricultural insurance is low and it is difficult to truly compensate farmers for their costs and losses. According to estimates of the Ministry of Finance, the gap between the level of agricultural insurance protection and direct materialization costs is about $35 \%$.Secondly, a single premium subsidy method is still used, so that companies that run agricultural insurance lack enthusiasm. It also made the agricultural insurance supply less competitive, which greatly affected the coordinated development of agricultural insurance supply and demand. Third, there is a lack of difference between subsidy standards and subsidy policies. 
Insurance premium rate, premium subsidy lack of differential preferential treatment. Regardless of the economic basis of the counties and cities, it is stipulated that a fixed share of the principle of the Premium subsidy. Therefore, there is a lack of consideration of the financial constraints of poverty-stricken counties' local policies. Finally, there is not enough incentive for agricultural insurance subsidies. Due to the current low rate of subsidy for agricultural subsidies, single subsidy items, and the limited financial abilities of local governments, agricultural insurance has insufficient incentives for farmers, insurance companies, or local governments, and their participation in agricultural insurance is not high.

\section{B. Agricultural Insurance Single and Low Coverage}

At present, policy-based agricultural insurance is still the main policy in China, and most of the commercial insurance agencies are reluctant to enter agricultural insurance. As a result, agricultural insurance products are single, premiums are high, and coverage is limited. Many poor regions cannot even enjoy agricultural insurance services. In particular, the degree of protection and coverage of special agricultural insurance products is not high. There are currently 16 types of financial subsidies in agricultural insurance, and the number is relatively small. Although a number of special farm insurance products have been designed for each pilot area, they are still relatively inadequate relative to the largescale poverty-stricken areas throughout the country. In addition, there are large differences in planting varieties and aquaculture varieties across the country. The number of specialty agricultural insurance products is still relatively small, and it is difficult to meet the needs of rural households across the country to develop characteristically enriched agriculture. Secondly, the coverage of some of the specialty agricultural insurance products is limited to natural risks, the degree of protection is not high, and the problems such as relatively simple rates and higher deductibles have caused farmers' willingness to participate in insurance policies to decline. In addition, there are some factors such as poor publicity of agricultural insurance products or sales in pilot areas, which virtually reduces the coverage and coverage of special agricultural insurance.

\section{Agricultural Insurance Funds Investment and Financing Project Channels Are Relatively Single and the Selection Criteria Are not Clear}

First of all, from a nationwide perspective, agricultural insurance directly participates in the project investment and financing of poverty-stricken areas is still limited to a few individual pilot areas, and the funds flow mainly to the local individual leading enterprises and large agricultural households to expand production financing, individual industrial upgrading of individual pilot villages, and other financing needs, therefore the methods and channels are relatively simple. Considering the risks and the long payback period, the participation of insurance capital in infrastructure is not highly regarded, and the degree of participation in the construction of industrial parks in poverty-stricken areas is still far behind. Secondly, some insurance institutions will invest agricultural insurance funds in poverty-stricken areas only as a simple short-term impulse to respond to policy calls, regardless of cost and revenue, and unwilling or having no patience to seriously examine the project's costs and benefits. Finally, the selection criteria for some insurance institutions' agricultural insurance funds investment and financing projects are not clear enough. Meanwhile, it is not decisive enough to consider how to prioritize economic and social benefits. Therefore, it is easy to cause the special poverty alleviation fund to make ends meet and project follow-up funds cannot be put in place, which affects the direct participation of agricultural insurance funds in investment and financing.

\section{Farmers Don't Know Enough about Insurance}

Since farmers have little knowledge of insurance, there is a chance of being unwilling to insure, and when disaster strikes, they send all hope to the government for relief. There are also some farmers who have misunderstood the insurance and think that the premium paid is useless and they think that they cannot have a disaster. Some rural households cannot correctly distinguish between property insurance and personal insurance. They think that insurance is a kind of savings. If there is no accident in the current year, the insurance premiums paid cannot be returned, and it is considered that the insurance is a non-discretionary assessment fee. These misunderstandings have caused some difficulties in the promotion of agricultural insurance and the realization of poverty alleviation through insurance.

\section{E. Central Government Subsidies Are Insufficient, Single and Unstable}

The development of agricultural insurance is closely related to national policies. Since the Central Document No.1 first proposed in 2004 that "conditional places can provide certain premium subsidies for farmers participating in planting insurance," The pilot work on premium subsidy for policy-related agricultural insurance in China was gradually carried out. Although the number of subsidy varieties has increased to 15 in 2015, and the pilot subsidy has been expanded to 29 provinces and districts, the proportion of subsidies for planting premiums has increased to more than $35 \%$. However, because of the subsidy insurance is mainly targeted at the mainstream farming industry, single and not stable enough. It has seriously affected the development of China's agricultural insurance. Firstly, comparing with the poor income of poor residents and poor economic foundation, the ratio of $35 \%$ to $40 \%$ of premium subsidies is still insufficient, especially in the early stage of precision poverty alleviation work. Secondly, for the sake of preventing moral hazard, the central government still adopts China's policybased agricultural insurance premium subsidy, and implements the "layered subsidy + subsidy linkage mechanism". That is, whether the subsidies of the central and provincial finances are in place depends on whether the local farmers pay their premiums and whether the primary financial subsidies are in place. In practice, county-level finances in poverty-stricken areas are often unable to bear local subsidies for $10 \%-20 \%$, which in turn leads to poverty alleviation. Agricultural insurance cannot be implemented on the ground. When poverty alleviation entered a new era of 
accurate poverty alleviation, although some pilot regions reformed the subsidy mechanism and achieved good results in the poverty pilot areas, but from the overall situation of the national poverty alleviation work, the central government's subsidy mechanism still has problems such as inadequate intensity, singleness, and lack of stability, directly affecting the enthusiasm of agricultural insurance institutions to develop special insurance, and many poverty-stricken demanding people with low incomes. Farmers are excluded from the agricultural insurance system.

\section{The AdVICE ON STRENGTHENING AgRiCUltural INSURANCE TO PROMOTE ACCURATE POVERTY ALLEVIATION}

\section{A. The Government Implements a Precise Support Policy}

At the level of government financial subsidies, Government financial subsidies must be led by the government because of the Agricultural insurance precision poverty alleviation having strong positive externalities. From the premium subsidies to the establishment of a catastrophe risk fund, we cannot leave the government's financial support and guarantees. Only with the backing of the government can we ensure that the national poverty alleviation and development policies are implemented. In particular, the poverty-stricken counties themselves have financial difficulties, and their ability to subsidize agricultural insurance premiums is relatively weak. The failure of fiscal subsidies to be put in place in time will restrict the smooth development of agricultural insurance and thus affect the effect of precision poverty alleviation.

First of all, it is necessary to increase the correct understanding and attention of local governments at all levels to the accurate poverty alleviation role of agricultural insurance, improve financial support policies, create a favorable external environment for the development of agricultural insurance, and guide the orderly development of agricultural insurance business. Here, we can innovate the management mode of poverty alleviation funds and also we can guide and encourage the allocation of a certain percentage of the poverty alleviation fund as a premium subsidy through the combination of insurance function and poverty alleviation development, and give full play to the amplification effect of the poverty alleviation fund. With regard to the support of insurance varieties, we can find the planting and breeding industry that can help them out of poverty as a wealth-generating industry according to the actual situation in the poverty-stricken areas, and we can include agricultural insurance in the category of subsidies for central government premiums, promote the development of related poverty-relief products, and enlarge the wealthgenerating industries.

\section{B. Accelerate the Design Process of Special Insurance and Increase the Coverage}

Governments at all levels must fully understand the significance and role of agricultural insurance, earnestly implement the national policy of strengthening agriculture and benefiting agriculture, and make good use of financial subsidies for agricultural insurance. In order to comply with the accuracy requirements of the Agricultural Insurance Benefiting Poverty Alleviation Program, the insurance company must first accelerate the process of designing special insurance products, and investigate the development direction and development of planting and breeding industries in different regions and work deeply. We will create more relevant agricultural insurance products tailored for the characteristics of agriculture, weigh the risks and benefits, and determine reasonable rates and coverage based on data analysis and past experience. Secondly, it should pay attention to the situation in which farmers' interest in insurance costs and output falls, and to insure the scope of protection is gradually extended to market risks, and the degree of protection is gradually increased. At the same time, products with different rates and amounts of insurance can be provided for farmers to choose.

In a word, the purpose of "precision" in the design of agricultural insurance products is to design products that fit the local realities, urgent needs of farmers, affordable living, and critical moments." Precision" requires not only a rapid increase in the number of products, but also an increase in the quality of products, so as to further increase the amount of coverage and coverage, "Precision" requires not only a rapid increase in the number of products, but also an increase in the quality of products, so as to further increase the amount of coverage and coverage, making the characteristic industries in the poverty-stricken areas are carried out smoothly under the escort of insurance." Increase in value added" and "tailored" put forward higher requirements for the insurance company's professional technology undoubtedly, and it needs the coordination of the government and other financial institutions.

\section{Strengthen Infrastructure Construction and Basic \\ Service Construction in Poverty-stricken Areas}

Poor infrastructure is the biggest constraint to economic development in poor areas. By analyzing the causes of poverty in impoverished areas; it is often related to the backwardness of infrastructure construction. And Infrastructure construction can directly affects the ability of poor residents to make their own blood to get rid of poverty. Therefore, we must unswervingly implement the "basis first" strategy. For instance, the agricultural insurance policy that should have been supported by a large number of fruit farmers has actually been met with cold shoulders. The peasant households are much less consulted, and the main reason for influencing the farmers' participation is that the fluctuation of the product sales price leads to the decrease of the yield rate. If farmers insure the local economic crops, they will undoubtedly increase spending. Poor sales channels and the lack of a deep-processing industrial chain directly affect the local characteristics of the cash crops, which in turn results in the poor implementation of preferential agricultural policies and the unacceptability of agricultural insurance products.

The inconvenience of transportation and the difficulty in accessing the power network not only bring inconvenience to the residents' production and life, but also virtually increase 
the time cost of obtaining agricultural information and financial support resources. Poor infrastructure has also increased the difficulty of attracting investment, which has greatly delayed the progress of poverty eradication. Therefore, increasing the investment and construction of local infrastructure such as roads, Water, electricity and communications will undoubtedly become the primary force for poverty alleviation. We can create a relatively good investment environment, and then play a leverage role in poverty alleviation funds, promote other social capital inflows, promote economic development in poverty-stricken areas and the industry out of poverty. At the same time, the active implementation of agricultural insurance poverty reduction projects and the expansion of agricultural insurance coverage have helped to increase the repayment rate of small loans and have had a positive impact on the healthy development of mutual aid funds in poor villages. In addition, agricultural insurance coverage is provided for the production and construction of poverty-stricken areas, and agricultural insurance investment funds provide a virtuous circle for the production and construction of poverty-stricken areas to aid the life.

\section{Strengthening Accurate Insurance Education in Poor Areas}

In most of the poor areas of China, influenced by the planned economy, the small-scale farmers' consciousness is deeply ingrained, and there is a general "wait and see" strategy. People are used to the risks and losses and are accustomed to resignation. At the same time, because of geographical and some objective conditions, farmers in remote and impoverished areas do not understand or even do not know about agricultural insurance, and they cannot agree with insurance. Therefore, one of the main tasks of precision poverty alleviation for agricultural insurance is to increase the propaganda of agricultural insurance. It is necessary to make full use of media such as television and the Internet to publicize the safeguard role of agricultural insurance by explaining the typical cases that have taken place around us so that everyone can understand the benefits of agricultural insurance. It can also help farmers count the economic accounts, eliminate luck, improve farmers' awareness of risk management and insurance awareness, increase the sense of identity and participation of poor people in agricultural insurance, gradually cultivate their insurance spending habits, and change their needs. We must change the ideological concept of "relying on other people" and promote the concept of poverty-stricken people to change from "seeking a government out of trouble" to "seeking insurance when an accident occurs", guide the masses to take the initiative to demand prosperity, and increase the capacity for selfdevelopment in poor areas.

\section{E. Establish Incentive and Restraint Mechanisms for Poverty Alleviation Protection}

The central government should expand its subsidy on agricultural insurance in the pilot areas; change the model of traditional subsidies, etc. These measures will greatly mobilize the enthusiasm of the supply and demand sides of the agricultural insurance market in the poverty-stricken areas, which in turn will strongly support the development of the specialized planting industries in poor areas. However, it also faces the problems of local fiscal operation risks and the moral hazard of insurance companies. Therefore, it is necessary to establish a complete incentive and restraint mechanism for poverty alleviation protection as a supporting measure for fiscal subsidies to "increase and improve quality" measures.

\section{CONCLUSION}

In view of this, we must firstly speed up the legislative process of agricultural insurance poverty alleviation norms, specify the government's insurance poverty alleviation responsibilities, and the main body of insurance agencies, social organizations, and other insurance and poverty alleviation obligations and legal responsibilities for noncompliance.Secondly, it accelerated the construction of grass-root poverty alleviation funds project management platform, strengthened the investigation and correction of illegal operations in poverty-stricken areas, and always kept strict control on poverty-relief funds.Finally, in the evaluation of poverty alleviation work, a positive incentive mechanism and a dereliction duty punishment mechanism should be established. According to the actual situation of the poverty-relief region, the task criteria should be clearly considered, and strict supervision and supervision of inspections and supervision inspections should be strictly implemented to fully implement the responsibilities to people. To achieve the objectives of clear standards and clear rewards and penalties in the assessment of poverty alleviation work, we should enhance the transparency of the use of poverty alleviation subsidies, and ensure that all policies and measures for accurate poverty alleviation and accurate poverty reduction are put in place.

\section{REFERENCES}

[1] Zheng Jun, Yang Xuefang, The Accurate Poverty Alleviation Effect of Zheng Agricultural Insurance:International experience and inspiration[J].Journal of Yan'an University (Social Sciences Edition)2018,40(01):77-82

[2] Tan Zhenghang, Perfection of China's Agricultural Insurance and Poverty-stricken Area and Improvement of Legal Guarantee Mechanism from the Perspective of Precise Poverty Alleviation[J]Lanzhou Journal.2016(09):167-173

[3] Tang Xuan,Research on Precision Poverty Alleviation Efficiency of Agricultural Insurance[D]Anhui University of Finance and Economics, 2017.

[4] Li Tao, Xu Xiang, Sun Shuo.Inclusive Finance and Economic Growth[J]Financial Research,2016(04):1-16. 